\title{
Transdisciplinaridade: frente e verso do que sou
}

\author{
Álvaro Augusto Schmidt Neto*
}

\section{Resumo}

O objetivo desse texto é descrever a dinâmica do desenho (estratégia de arte educação), analisando sua aplicação e desenvolvimento em grupos de conversação em um hospital na cidade de São Paulo. Após a aplicação em mais de trinta grupos, selecionamos alguns episódios que indicam a coerência dessa dinâmica com os princípios da transdisciplinaridade e a possibilidade dessa estratégia ser aplicada em diferentes ambientes de aprendizagem.

Palavras-chave: Transdisciplinaridade. Dinâmica pedagógica. Autoconhecimento.

\section{Transdisciplinarity: front and back of who i am.}

\section{Abstract}

The aim of this text is to describe the dynamics of drawing as a strategy of art education, analyzing its application and development in conversation groups at a hospital in São Paulo city. After the application in more than thirty groups, we have assembled some episodes that indicate the coherence of this dynamic with the principles of transdisciplinarity and the possibility of this strategy to be applied in different learning ambiences.

Keywords: Transdisciplinarity. Pedagogical dynamics. Self knowledge.

\section{Transdisciplinariedad: anverso y reverso do que soy}

\section{Resumen}

El objetivo de este texto es describir la dinámica del dibujo (estrategia del arte educación), analizando su aplicación y desarrollo en grupos de

Doutor em Educação, pela PUC/SP. Educador e Coach Corporativo no Hospital de Transplantes Euryclides de Jesus Zerbini (SPDM). Pesquisador do grupo de pesquisa Gepec/UMESP-CNPq.

Email: profalvaroneto@hotmail.com 
conversación en un hospital de la ciudad de São Paulo. Después de la aplicación en más de treinta grupos, seleccionamos algunos episodios que indican la coherencia de esta dinámica con los principios de la transdisciplinariedad y la posibilidad de que esta estrategia se aplique en diferentes ambientes de aprendizaje.

Palabras-llave: Transdisciplinariedad. Dinámica pedagógica. Autoconocimiento.

\section{Introdução}

Segundo Basarab Nicolescu (2002), a transdisciplinaridade se constrói a partir de três princípios: a complexidade, os níveis de realidade e a lógica do terceiro incluído. Assim, ela concebe a realidade em seu contexto complexo e não no contexto simplificado e fragmentado da visão cartesiana. Isso significa que ela examina a realidade em seu todo e em suas partes e não restringe posições, visões e concepções específicas. Ela procura contemplar a realidade em seu contexto multidimensional, incluindo os opostos e os contraditórios, assim como a natureza, em seus movimentos ecológicos, está sempre lidando com elementos de consenso e conflito e vivendo o jogo de tensões entre diferentes polos.

Diferentemente da concepção positivista da ciência do século XIX, a transdisciplinaridade concebe a realidade formada por diferentes planos de realidade. Isso permite uma visão não só mais ampla, mas oferece a perspectiva da profundidade, uma vez que consegue perceber significados de um objeto que estão além do fenômeno, ou daquilo que aparece num primeiro momento. Podemos, por exemplo, analisar a educação sob o ponto de vista econômico e descrever sua importância no contexto do desenvolvimento do país. Mas num outro plano de realidade, podemos analisar essa mesma educação sob o ponto de vista do desenvolvimento do sujeito e perceber até que ponto as competências que estão sendo construídas favorecem o despertar de sua consciência espiritual, por exemplo. Isso significa que algumas ações educacionais podem ou não ser favoráveis ao sujeito, dependendo do plano de realidade que estamos analisando. Por isso, uma perspectiva mais ampla e 
complexa ajuda a criarmos uma visão transdisciplinar da educação, pois podemos contemplar a amplitude e o alcance das filosofias educacionais em diferentes âmbitos e em suas múltiplas aplicações.

A lógica do terceiro incluído é na verdade a consequência dos dois primeiros princípios, o da realidade complexa e o dos diferentes níveis de realidade, pois ela inclui uma possibilidade que não é considerada numa visão de realidade fragmentada e binária. Por exemplo, numa visão simplificada e reducionista, o aluno só pode ser aluno e está excluída a possibilidade dele ser professor. Ou seja, o aluno só pode aprender e não pode ensinar. Na lógica do terceiro incluído o aluno também é professor quando chega em casa e fala o que aprendeu para o seu irmão ou para a sua mãe. Ou seja, no plano da realidade da sala de aula o aluno talvez seja apenas aluno, mas no plano da realidade do convívio com os colegas ou com sua família o aluno pode assumir o papel de um professor. Desse modo, dependendo do plano de realidade a que estamos nos referindo o aluno é professor e o professor é aluno. Essa afirmação parece contraditória num plano de realidade, mas perfeitamente correta e verdadeira num outro. Por isso, olhar a realidade em sua complexidade amplia nossa perspectiva de significados e compreensão dos diferentes planos de realidade. Permite ainda a aceitação de uma lógica que supera a linearidade binária a que fomos - e ainda somos em alguns casos - submetidos em nossa formação escolar.

\section{A transdisciplinaridade aplicada}

A questão que queremos discutir nesse texto é como criar estratégias pedagógicas que possam, de modo prático e objetivo, contemplar os princípios da transdisciplinaridade. Como criar uma dinâmica pedagógica que respeite a complexidade da realidade, os diferentes planos de realidade e a lógica do terceiro incluído?

Primeiro acreditamos, como nos ensina Moraes (2008), que a transdisciplinaridade implica numa atitude, onde o sujeito que se propõe a desenvolver um trabalho transdisciplinar conceba a realidade como complexa e analise o fenômeno que se apresenta em 
diferentes perspectivas, fazendo uso da lógica do terceiro incluído. Essa atitude é fundamental, pois não basta conhecer teoricamente os princípios transdisciplinares, é preciso vivenciá-los em sua integralidade existencial.

Outro aspecto importante é centralizar o sujeito e trabalhar a partir daquilo que ele traz e lançar indagações que favoreçam o desenvolvimento de uma visão transdisciplinar. Em nosso trabalho junto a grupos de conversação, percebemos que as pessoas ficam extremamente gratas e felizes quando conseguem enxergar um ponto de vista novo sobre o objeto que estudam. Uma nova perspectiva é algo que a transdisciplinaridade oferece, e por isso mesmo transforma as pessoas de modo rápido e convincente, porque abre uma perspectiva inteligente e inédita para o sujeito. Respostas criativas para os problemas corriqueiros agradam a quase todos. As respostas prontas nos cansam e nos condicionam a uma zona de conforto, enquanto as respostas novas e criativas abrem possibilidades e perspectivas que animam nossa imaginação e provocam nossa inteligência a superar as dificuldades que a vida nos apresenta.

O terceiro aspecto é estarmos abertos para o contexto da aprendizagem, eliminando posturas pretenciosas com o uso de respostas prontas e definidas. Essa abertura implica estarmos prontos para sermos surpreendidos por questões e situações que nos provocam a lidar com novos planos de realidade e diferentes perspectivas, a não virar as costas para aquilo que não compreendemos ou não concordamos. É serenar o olhar julgador e fundamentado em nosso modelo mental e abrir um leque de perspectivas que ultrapassam nossos conceitos, valores e crenças já estabelecidos. Talvez o conceito que mais se aproxime disso seja o de "respeitar o outro como um legítimo outro" proposto por Humberto Maturana. Conceito bonito quando falado e dificílimo de ser vivido. Esse é, na verdade, o grande desafio: assimilar e viver a transdisciplinaridade em sua amplitude, com todas as incertezas e surpresas que se descortinam na nossa atitude e disposição para com nós mesmos, para o outro e para a realidade. 


\section{A dinâmica do desenho}

Nos grupos de conversação que coordenamos no Hospital de Transplantes Euryclides de Jesus Zerbini, localizado na cidade de São Paulo, criamos a dinâmica do desenho, que se mostrou uma estratégia extremamente rica de acolhimento do sujeito e um catalisador dos sentimentos que envolvem um colaborador da saúde no seu ambiente de trabalho.

Numa sala dispomos os participantes em círculo e, depois das apresentações formais e de uma fala rápida de cada participante expressando o seu momento, iniciamos o trabalho propondo que cada sujeito desenhe numa folha de sulfite como ele é visto pelo hospital ou como as pessoas te veem no hospital? A ideia é que o sujeito represente, através do desenho, o modo como ele acha que é visto pelas pessoas que trabalham com ele.

Depois dessa etapa, pedimos para os participantes virarem a folha e no verso desenharem como eles gostariam de ser vistos. Temos assim na mesma folha duas visões do mesmo sujeito apresentadas pelo próprio sujeito. Aqui o participante já percebe que há pelo menos duas formas de ser visto e já iniciamos o despertar para uma consciência da complexidade.

O próximo passo na dinâmica é pedir para os participantes falarem sobre os seus desenhos. Nesse momento o facilitador pode escolher se irá ou não pedir para todos falarem. Isso depende do tamanho do grupo e do tempo disponível que temos para trabalhar.

Num dos grupos que orientamos, uma participante desenhou primeiramente um colete azul e, no verso, desenhou ela mesma vestida com o colete azul. O colete azul, para aqueles que não estão familiarizados, é o uniforme padronizado da enfermeira, o que significa que ela é vista apenas como um colete, ou seja, como uma enfermeira. E ela gostaria de ser vista como uma enfermeira com um nome, personalidade e identidade. Esses últimos atributos foram excluídos, segundo a participante, das suas relações com os pacientes e colegas de trabalho. O interessante dessa dinâmica é que quando a participante descreve o seu desenho para o grupo, os demais participantes 
se identificam com a colega e reconhecem que muitas vezes também são vistos apenas como uma função e não como uma pessoa. Não há nada mais cartesiano e limitante do que isso!

Num outro grupo, na frente da folha um rapaz desenhou um aparelho de raio-x, e no verso desenhou ele mesmo. Na apresentação do seu desenho ele afirmou que ele é visto como o rapaz do raio-x e que gostaria de ser visto como uma pessoa. A ideia de reduzir o sujeito à profissão que ele exerce é isolá-lo do contexto do seu trabalho. $\mathrm{O}$ ambiente de um hospital espelha relações complexas, que envolvem diferentes áreas e expertises que precisam interagir para a segurança e benefício do paciente. Quanto mais inteiro o profissional for visto, mais seguro estará o paciente e mais fácil serão as relações entre todos os envolvidos. O rapaz do raio-x não é um complemento do aparelho de raio-x, ele é uma pessoa que manipula o aparelho e que pode, além de tirar chapas, saber acolher o paciente e estar disposto a interagir com as outras pessoas das outras equipes de trabalho.

Uma enfermeira participante dessa dinâmica, encheu a frente da sua folha de bolinhas, e no verso desenhou uma bolinha, um triângulo, um quadrado e um retângulo. Ao explicar o seu desenho, ela disse que é vista como uma bolinha igual a todas as outras bolinhas, as outras enfermeiras. Ela gostaria de ser vista como um triângulo ou um retângulo, ou seja, como uma pessoa com características próprias. Ou seja, apesar de termos funções padronizadas nas organizações, as pessoas podem interpretar e traduzir as condutas e exercê-las com presença e sentido, sem necessariamente, se condicionarem a meros reprodutores de protocolos e condutas. Saber fazer é excelente, mas saber porque está fazendo é ainda melhor!

Numa dinâmica aplicada para um grupo de gestores, um médico, diretor do hospital, desenhou na frente seu crachá, com foto, nome e a função: diretor. No verso ele fez um autorretrato com os braços abertos oferecendo um abraço. As funções e os papeis hierárquicos estabelecidos nas organizações muitas vezes inibem relações humanas mais abertas e sinceras. Ver o outro como chefe ou 
subordinado muitas vezes encobre diálogos que poderiam ser mais objetivos e produtivos. O participante queria dizer a todos: não me vejam apenas como o diretor, mas antes como um amigo e um colega. Nas visões parciais e apegadas que normalmente estabelecemos nas corporações, muitas vezes, até mesmo aqueles que estão nos mais altos cargos sofrem a solidão de serem apenas um crachá.

\section{Um detalhe relevante}

Quando propomos o desenho da frente - como as pessoas te veem no hospital? - normalmente os participantes se sentem desconfortáveis e alguns chegam a reclamar que o exercício é difícil e que não sabem desenhar. Aos poucos vão se concentrando e sempre conseguem realizar a proposta. Quando todos terminam o facilitador pede para que virem a folha e desenhem no verso como eles gostariam de ser vistos. Esse momento surpreende a todos e nunca aconteceu de ouvirmos queixas, ao contrário, todos estão contentes e animados a cumprir essa etapa. Mostrar como eu sou visto é sempre desconfortável, enquanto desenhar como gostaria de ser visto é prazeroso. $\mathrm{O}$ verso do desenho espelha um sujeito valorizado, com voz e convidado a transcender os limites do cargo, da função, das regras e dos controles. É um contraponto necessário para a aceitação incondicional de si mesmo!

\section{Considerações finais}

Essa dinâmica mostra entre outras coisas o quanto as pessoas estão isoladas e escondidas no ambiente de trabalho. Mostra também que é difícil verbalizar os nossos sentimentos e quando propomos o desenho, os participantes se sentem mais à vontade para expressarem o que realmente sentem com relação aos outros e a si mesmo.

Apesar de simples, essa dinâmica permite aos participantes perceberem a complexidade da realidade, uma vez que abre a perspectiva de se colocarem e de perceberem os demais colegas, o que nem sempre é possível nas rotinas de trabalho. Essa dinâmica 
mostra aos participantes que trabalhar não é apenas desempenhar uma função, mas também deve ser um momento de interação, de aprendizagem, de crescimento, de amadurecimento e de catalisação de sentimentos.

A dinâmica abre ainda a possibilidade da percepção de outros planos de realidade, primeiro ao propor um trabalho centrado no sujeito - uma vez que a maioria dos "treinamentos" focam a assimilação de habilidades e a transmissão de informações e dados - e segundo porque permite aos participantes perceberem seus colegas sob um outro ponto de vista, já que de fato, muitas vezes costumavam considerar a enfermeira como uma "bolinha" e o rapaz como o "menino do raio-x". E como não pode deixar de ser, acabamos olhando para nós mesmos e percebendo o quanto também somos "bolinhas" e "coletes azuis". Isso permite aos participantes desenvolverem um novo olhar sobre si mesmos e sobre os colegas. Assim, outros planos de realidade se descortinam e iluminam o ambiente padronizado e desumanizado, que a ideologia da produtividade e dos resultados insiste em rotular como a única e absoluta.

A partir dessa dinâmica, a lógica do terceiro incluído nasce no mesmo instante em que a lógica binária sucumbe. Imaginar que a moça de colete azul é enfermeira e não pode ser outra coisa; que o rapaz do raio-x só pode ser aquele que tira chapas, é fruto de nossa formação, onde as coisas são o que são e não podem ser outra que aquela que está definida a ser. Ou seja, é uma total falta de imaginação!

Certa vez, num grupo de coaching, estávamos desenvolvendo a dinâmica da história de vida e uma médica relatou que era dançarina de flamenco e fazia apresentações e participava de espetáculos. Quem poderia imaginar aquela médica, de jaleco branco, com estetoscópio no ombro, dançando música flamenca? Poder imaginar é abrir perspectivas, viabilizar possibilidades, sondar o impossível. Sem dúvida, somos mais que uma bolinha. 


\section{Referências}

MORAES, Maria Cândida. Ecologia dos saberes: complexidade, transdisciplinaridade e educação. São Paulo : Antakarana/WHH, 2008.

NICOLESCU, Basarab. "fundamentos metodológicos para o estudo transcultural e transreligioso". in: Educação e transdisciplinaridade II / coordenação executiva do Cetrans. São Paulo : Triom, 2002. 